[Agr. Biol. Chem., Vol. 36, No. 9, p. 1529 1535, 1972]

\title{
Conversion of Hypoxanthine Derivatives to Guanine Derivatives by Bacillus subtilis ${ }^{\dagger}$
}

\author{
By Yuichiro Midorikawa, Takashi AkiYa, Akira Kuninaka \\ and Hiroshi YosHino \\ Research Laboratory of Yamasa Shoyu Co. Lid., Choshi \\ Received January 7, 1972
}

\begin{abstract}
By successive mutagenic treatments including transduction with bacteriophage $\mathrm{SP}-10$, ultraviolet light irradiation and $\mathrm{N}$-methyl- $\mathrm{N}^{\prime}$-nitro- $\mathrm{N}$-nitrosoguanidine treatments, a mutant, strain No. 322, capable of converting exogenously supplemented hypoxanthine or inosine to guanine and guanosine, was derived from an adenine-less, IMP-producing mutant of Bacillus subtilis IAM 1145. Strain No. 322 was an adenine-leaky mutant lacking GMP-reductase, adenase, and 5'-nucleotidase. The strain effectively accumulated guanine and guanosine in the culture fuid, when grown in the presence of hypoxanthine or inosine, while it failed to convert exogenously supplemented IMP to the guanine derivatives.
\end{abstract}

In our laboratory, conversion of exogenously supplemented hypoxanthine and inosine to xanthine derivatives ${ }^{1 /}$ and succinyl adenine derivatives ${ }^{2)}$ by biochemical mutants of Bacillus subtilis has been demonstrated. Furthermore, the authors succeeded for the first time in conversion of the exogenous hypoxanthine derivatives to guanine derivatives using a mutant derived from Bacillus subtilis ${ }^{33}$ : In the attempts to obtain microorganisms capable of producing guanine derivatives, the authors derived various mutants from strain A-1-25 of Bacillus subtilis IAM 1145 which is an adenine-requiring mutant with weak $5^{\prime}$-nucleotidase, and found that both GMP-reductaseand adenase-lacking and adenine-requiring or leaky mutants converted the exogenous hypoxanthine or inosine to guanine and guanosine and accumulated these compounds in the culture fluid. Such conversion is interesting not only from the biological point of view but also from the industrial point of view. In this paper, the conversion by strain

$\uparrow$ This paper was presented at the Symposium on Amino Acid and Nucleic Acid, December, 1969.
No. 322, one of the most effective strains the authors derived, is discussed in detail.

In addition, Kanamitsu ${ }^{4)}$ reported that some mutants resistant to 8-azaguanine had ability to produce inosine and guanosine from hypoxanthine, guanine, and adenine.

\section{MATERIALS AND METHODS}

Organism. An adenine-requiring mutant with weak $5^{\prime}$-nucleotidase of Bacillus subtilis, strain A-1-25, was employed as the original culture. Induction of mutants was carried out by ultraviolet light irradiation and $\mathrm{N}$-methyl- $\mathrm{N}^{\prime}$-nitro- $\mathrm{N}$-nitrosoguanidine treatments. The genetic characters of mutants were examined by the reprica plating method. Transduction was performed by using bacteriophage $\mathrm{SP}-10$.

Media and bacterial growth. The medium for temporary maintenance of the culture, the inoculum medium, and the minimal medium used for both isolation of mutants and identification of nutritional requirments were the same as employed in the previous paper. $^{23}$ The standard production medium was composed of the following components in $\mathrm{g} /$ liter: $\mathrm{KH}_{2} \mathrm{PO}_{4}$; 4, $\mathrm{K}_{2} \mathrm{HPO}_{4} ; 6, \mathrm{NH}_{4} \mathrm{Cl} ; 4, \mathrm{Na}$-citrate;, $\mathrm{MgSO}_{4} \cdot 7 \mathrm{H}_{2} \mathrm{O}$; 0.2 , amino acid mixture; 10 , yeast extract; 5 or 10 , and glucose; 100. The pH was adjusted to 6.8. Each cultivation was carried out at $30^{\circ} \mathrm{C}$ in a $500-\mathrm{ml}$ Erlen- 
meyer flask containing $30 \mathrm{ml}$ of medium on a reciprocal shaker.

Analytical methods. Identification of purine derivatives was carried out by paper chromatography, paper electrophoresis and UV spectrophotometry.

\section{RESULTS}

Derivation of mutants and their guanine derivatives productivity

The metabolic pathway of purine biosynthesis $^{6)}$ suggests that guanine derivatives productivity of a bacterial mutant is mainly related to its GMP-reductase activity. In order to confirm this possibility, various mutants lacking GMP-reductase were derived from strain A-1-25 as shown in Fig. 1. Each of the derived GMP-reductase-lacking mutants was grown in a production medium with and without hypoxanthine. UV-absorbing compounds in the culture supernatant were analyzed. The results are summarized in Table I. Strain RNA-3 and No. 322 did not produce any UV-absorbing compounds in the
Table I. Production of Guanosine by Several Mutants Derived From STrain A-1-25

A production medium containing $5 \mathrm{~g}$ /liter of yeast extract was used. Supplementation of hypoxanthine was performed at 0 time. Cultivations were carried our for 4 days at $28^{\circ} \mathrm{C}$.

\begin{tabular}{lccc}
\hline Strain & $\begin{array}{c}\text { Hyp (7 mM) } \\
\text { supplemen- } \\
\text { tation }\end{array}$ & $\begin{array}{c}\text { Guo (mm) } \\
\text { produced }\end{array}$ & $\begin{array}{c}\text { Hyp and } \\
\text { Ino (mM) } \\
\text { remaining }\end{array}$ \\
\cline { 2 - 4 } HRN-7 & - & 0 & 0 \\
RN-2 & + & 0 & 6.8 \\
RNA-3 & - & 0 & 0 \\
RNA-3-33 & + & 0 & 6.5 \\
No. 322 & - & 0 & 0 \\
& + & 2.3 & 4.3 \\
& + & 3.3 & 4.0 \\
& + & 4.0 & 10.8 \\
& + & 0 & 0 \\
\hline
\end{tabular}

absence of hypoxanthine, but in the medium supplemented with hypoxanthine they consumed hypoxanthine supplemented and produced guanosine equivalent to the amount of hypoxanthine consumed. The data suggest

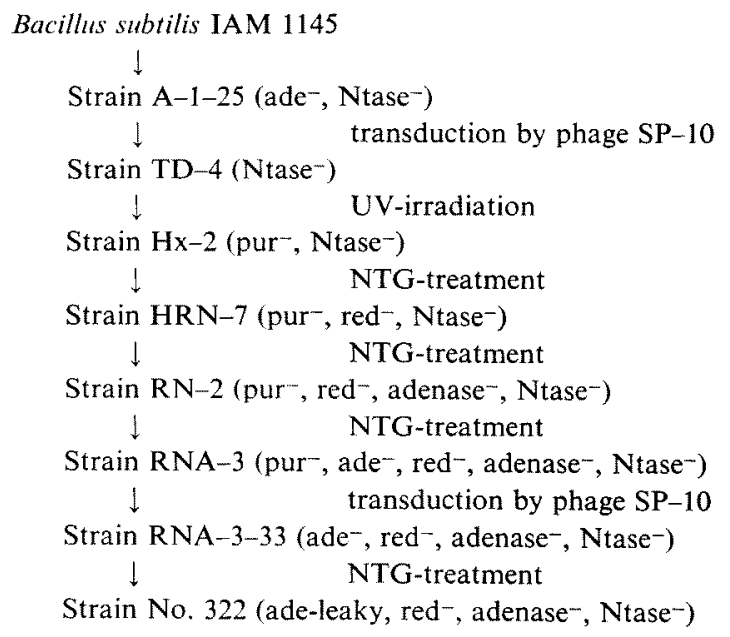

FIG. 1. Derivation of Mutants Producing Guanine Derivatives. Genotypes were indicated in parentheses.

The following symbols are used throughout all figures and tables in this paper: Ade, adenine; Gua, guanine; Hyp, hypoxanthine; Guo, guanosine; Ino, inosine; Pur, purine; Ntase, nucleotidedegrading activity; red, GMP reductase; and NTG, N-methyl-N'-nitro-N-nitrosoguanidine. 
that these mutants converted hypoxanthine to guanosine. It is noteworthy that the conversion was almost quantitatively carried out by strain No. 322. The growth of this strain was very slow in a minimal medium but was stimulated by supplementation of adenine (Fig. 2). Thus, this strain is regarded as an adenine-leaky mutant. The results shown in Fig. 1 and Table I indicate that combination of GMP-reductase-lacking and

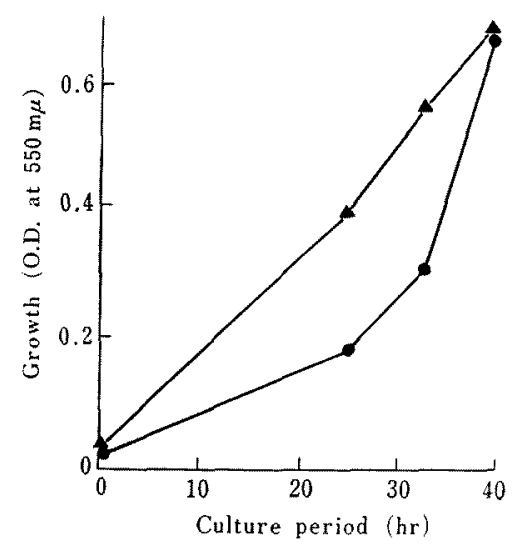

Fig. 2. Growth Response of No. 322 to Adenine.

Cultivation was carried out at $28^{\circ} \mathrm{C}$ in a minimal medium with $50 \mu \mathrm{g} / \mathrm{ml}$ of adenine $(\mathbf{A}-\mathbf{A})$ or without adenine (-0).

adenine-requiring or adenine-leaky characteristics in a mutant may be a prerequisite for its salvage synthesis of guanosine from hypoxanthine. In addition, it is interesting that strain RNA-3-33 not only produced hypoxanthine derivatives de novo but also converted them to guanosine.

\section{Conversion of hypoxanthine derivatives to} guanine derivatives by strain No. 322

As strain No. 322 seemed to be able to convert the exogenous hypoxanthine quantitatively to guanosine (Table I), possibility of the conversion of exogenously supplemented inosine or IMP to guanine derivatives was studied. Strain No. 322 was grown in a production medium supplemented with $14 \mathrm{~mm}$ of hypoxanthine, inosine or IMP for 5 days at $30^{\circ} \mathrm{C}$. As shown in Table II, guanine and guanosine were accumulated in the hypoxanthine-supplemented medium and guanosine alone in the inosine-supplemented medium. In the IMP-supplemented medium, however, any significant amounts of guanine derivatives were not recognized and IMP remained quantitatively in the culture fluid. GMP was not produced in any case. The data given in Table II also indicate that formation of guanine derivatives by this strain was nearly quantitatively accompanied with disappearance of hypoxanthine derivatives. This phenomenon suggests that guanine derivatives were formed

Table II. Production of Guanine Derivatives from Hypoxanthine Derivatives by No. 322

A production medium containing $5 \mathrm{~g} /$ liter of yeast extract was used.

Hypoxanthine derivatives were added at 0 time.

Cultivations were carried out for 5 days at $28^{\circ} \mathrm{C}$.

\begin{tabular}{cllllll}
\hline $\begin{array}{c}\text { Added hypoxanthine } \\
\text { derivatives (14 mM) }\end{array}$ & \multicolumn{2}{c}{$\begin{array}{c}\text { Guanine derivatives } \\
\text { produced (mM) }\end{array}$} & \multicolumn{2}{c}{$\begin{array}{c}\text { Hypoxanthine derivatives } \\
\text { remaining (mM) }\end{array}$} \\
\hline & Gua & Guo & GMP & Hyp & Ino & IMP \\
\hline - & 0 & 0 & 0 & 0 & 0 & 0 \\
Hyp & 2.5 & 6.8 & 0 & 0 & 4.2 & 0 \\
Ino & 0 & 8.5 & 0 & 0 & 5.0 & 0 \\
IMP & 0 & 0 & 0 & 0 & 0 & 14.2 \\
\hline
\end{tabular}


from added hypoxanthine derivatives.

Influence of culture conditions on production of guanine derivatives from hypoxanthine or inosine by strain No. 322

a) Medium. In order to select a medium suitable for production of guanine derivatives from hypoxanthine, the effects of concentrations of several inorganic salts and yeast extract were examined. Production of guanine derivatives was not so much dependent on the concentration of ammonium chloride ( 2 to $8 \mathrm{~g} /$ liter $)$ or magnesium sulfate $(0.2$ to $2 \mathrm{~g} /$ liter). The ratio of guanosine and guanine produced was dependent on the concentration of phosphate, though the sum of them was not (Fig. 3). At a high concentration of

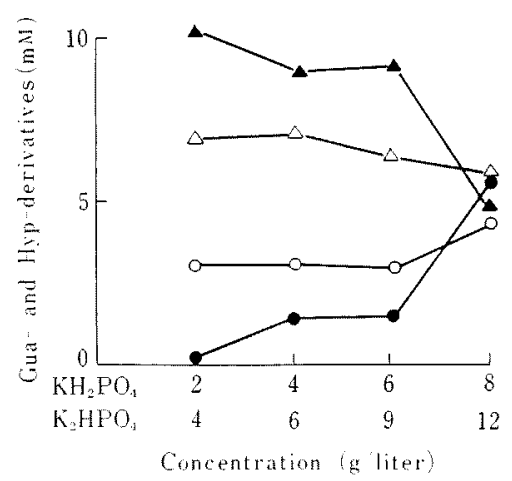

FIG. 3. Influence of Concentration of Phosphate on the Production of Guanine Derivatives from Hypoxanthine.

The cells of strain No. 322 were grown for 5 days at $28 \mathrm{C}$ in four production media each of which contained $5 \mathrm{~g} /$ liter of yeast extract, $21 \mathrm{~mm}$ of hypoxanthine, and the indicated amount of phosphate together with other usual components of standard production medium. After the cultivation, UV-absorbing compounds in the media were determined.

- $\bullet$ Gua, $\triangle-\Delta$ Guo, $\bigcirc-O$ Hyp, $\triangle-\triangle$ Ino.

phosphate, level of guanine produced was higher than that of guanosine produced, while at usual concentration of phosphate, the former was always much lower than the latter.
Probably at a high concentration of phos phate, guanosine that had once been formec was degraded to guanine by the action 0 nucleoside phosphorylase. Yeast extract alsc influenced production of guanine derivative: (Fig. 4): For the production of more that

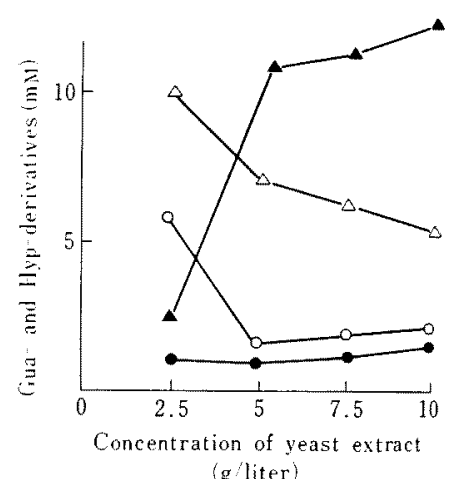

Fig. 4. Influence of Concentration of Yeast Extract on the Production of Guanine Derivatives from Hypoxanthine.

The cells of strain No. 322 were grown for 5 days at $28^{\circ} \mathrm{C}$ in four production media each of which contained $21 \mathrm{~mm}$ of hypoxanthine, and the indicated amount of yeast extract together with usual components of standard production medium. After the cultivation, UV-absorbing compounds in the media were determined.

Ino.

- - Gua; $\Delta-\Delta$, Guo; $\bigcirc-0$, Hyp; $\Delta-\Delta$;

$10 \mathrm{~mm}$ of guanosine, the presence of more than $5 \mathrm{~g} /$ liter of yeast extract in the initial medium was necessary. In order to reveal the effective elements in yeast extract, yeast extract in the production medium was replaced by the following purine and pyrimidine bases, vitamins and metal ions and their combinations: A mixture of $100 \mathrm{mg}$ each of adenine, guanine, xanthine and uracil dissolved in $20 \mathrm{ml}$ of $0.2 \mathrm{~N} \mathrm{NaOH}$ was used as the purine and pyrimidine bases. A mixture of $100 \mathrm{mg}$ each of $\mathrm{ZnCl}_{2}, \mathrm{CuSO}_{4}, \mathrm{NiCl}_{2} \cdot 6 \mathrm{H}_{2} \mathrm{O}, \mathrm{CoCl}_{2}$. $6 \mathrm{H}_{2} \mathrm{O}, \mathrm{FeCl}_{2} \cdot n \mathrm{H}_{2} \mathrm{O}, \mathrm{MnCl}_{2} \cdot 4 \mathrm{H}_{2} \mathrm{O}$ and $\mathrm{SnCl}_{2}$. $2 \mathrm{H}_{2} \mathrm{O}$ dissolved in $10 \mathrm{ml}$ of distilled water was 
used as the metal ions. A mixture of $10 \mathrm{mg}$ of thiamine $\mathrm{HCl}, 10 \mathrm{mg}$ of riboflavin, $10 \mathrm{mg}$ of nicotinic acid, $10 \mathrm{mg}$ of $p$-aminobenzoic acid, $10 \mathrm{mg}$ of Ca-pantothenate, $10 \mathrm{mg}$ of pyridoxine $\mathrm{HCl}, 10 \mathrm{mg}$ of pyridoxal $\mathrm{HCl}$, $2 \mathrm{mg}$ of folic acid, and $2 \mathrm{mg}$ of biotin dissolved in $50 \mathrm{ml}$ of distilled water was used as the vitamins. In place of yeast extract, $10 \mathrm{ml}$ of the purine and pyrimidine bases, $1 \mathrm{ml}$ of the metal ions, $5 \mathrm{ml}$ of the vitamins, or their combination was employed per 1 liter of a medium. Table III indicates that coexistence of the

\section{Table III. Effect of the Purine and Pyrimidine Bases, Vitamins and Metal IONS}

Yeast extract of the $28 \mathrm{~mm}$ hypoxanthine-supplemented production medium was replaced by the purine and pyrimidine bases, vitamins, and/or metal ions as described in the text. After cultivation of strain No. 322 for 5 days at $28^{\circ} \mathrm{C}$, the amounts of guanine derivatives in the medium were determined.

\begin{tabular}{lc}
$\begin{array}{c}\text { Replacement of } \\
\text { yeast extract }\end{array}$ & $\begin{array}{c}\text { Gua }+ \text { Guo } \\
\text { produced (mM) }\end{array}$ \\
\hline None & 0 \\
Bases & 0 \\
Bases + Vitamins & 0 \\
Bases + Metal ions & 7.5 \\
Vitamins & 0 \\
Vitamins + Metal ions & 0 \\
Metal ions & 0 \\
Metal +Bases + Vitamins & 11.8 \\
\hline
\end{tabular}

purine and pyrimidine bases and metal ions was indispensable for production of guanine derivatives and the vitamins were also effective only when coexisted with the purine and pyrimidine bases and the metal ions.

Omission tests of the purine and pyrimidine bases and the metal ions revealed adenine (Table IV) and $\mathrm{Mn}^{2+}$ or $\mathrm{Fe}^{2+}$ (Table V) were essential elements in the respective mixtures. Furthermore, the effective factor in the vitamins was concluded to be thiamine (Table VI). Thus, yeast extract could almost completely be

\section{Table IV. Effect of Indvidual Base}

Cultivation was carried out in a $28 \mathrm{~mm}$ hypoxanthine-supplemented production medium containing the vitamins, metal ions and an indicated base in place of yeast extract for 5 days at $28^{\circ} \mathrm{C}$.

\begin{tabular}{cc}
$\begin{array}{c}\text { Base } \\
\text { supplemented }\end{array}$ & $\begin{array}{c}\text { Gua }+ \text { Guo } \\
\text { produced (mM) }\end{array}$ \\
\hline None & 0 \\
Ade & 12.0 \\
Gua & 0 \\
Xan & 0 \\
Ura & 0 \\
\hline
\end{tabular}

Table V. EfFect of Individual Metal Ion

Cultivation was carried out in a $28 \mathrm{~mm}$ hypoxanthine-supplemented production medium containing the vitamins, bases and an indicated metal ion in place of yeast extract for 5 days at $28^{\circ} \mathrm{C}$.

\begin{tabular}{cc}
$\begin{array}{c}\text { Metal ion } \\
\text { supplemented }\end{array}$ & $\begin{array}{c}\text { Gua }+ \text { Guo } \\
\text { produced }(\mathrm{mM})\end{array}$ \\
\hline None & 0 \\
$\mathrm{Zn}^{2+}$ & 0 \\
$\mathrm{Cu}^{2+}$ & 0 \\
$\mathrm{Ni}^{2+}$ & 0 \\
$\mathrm{Co}^{2+}$ & 0 \\
$\mathrm{Fe}^{2+}$ & 9.5 \\
$\mathrm{Mn}^{2+}$ & 11.0 \\
$\mathrm{Sn}^{2+}$ & 0
\end{tabular}

TAble VI. EFFect of Individual Vitamin

Cultivation was carried out in a $28 \mathrm{~mm}$ hypoxanthine-supplemented production medium containing the bases, metal ions and indicated vitamin in place of yeast extract for 5 days at $28^{\circ} \mathrm{C}$.

\begin{tabular}{lc}
\multicolumn{1}{c}{$\begin{array}{c}\text { Vitamin } \\
\text { supplemented }\end{array}$} & $\begin{array}{c}\text { Gua }+ \text { Guo } \\
\text { produced }(\mathrm{mm})\end{array}$ \\
\hline None & 7.5 \\
Thiamine & 12.5 \\
Riboflavin & 7.0 \\
Nicotinic acid & 5.8 \\
p-Aminobenzoic acid & 6.5 \\
Ca-Pantothenate & 6.5 \\
Pyridoxine $\mathrm{HCl}$ & 5.8 \\
Pydidoxal $\mathrm{HCl}$ & 7.5 \\
Folic acid & 6.8 \\
Biotin & 6.8 \\
\hline
\end{tabular}


TABle VII. TransRibosidation from Guanosine to Hypoxanthine

To a test tube containing the starting materials dissolved in $2.0 \mathrm{ml}$ of $1 / 15 \mathrm{M}$ veronal-acetate buffer, pH 7.0, about $5 \times 10^{9}$ of washed cells of strain No. 322 suspended in $2 \mathrm{ml} \mathrm{of} 0.9 \% \mathrm{KCl}$ solution were added. The mixture was incubated at $32^{\circ} \mathrm{C}$ for $8 \mathrm{hr}$ with reciprocal shaking. After incubation, UV-absorbing products were analyzed.

\begin{tabular}{|c|c|c|c|c|}
\hline \multirow[t]{2}{*}{$\begin{array}{c}\text { Concentrations of } \\
\text { starting materials } \\
\mathrm{mM}\end{array}$} & \multicolumn{4}{|c|}{$\begin{array}{c}\text { Concentrations of } \\
\text { products } \\
\mathrm{mM}\end{array}$} \\
\hline & Hyp & Ino & Gua & Guo \\
\hline Hyp 20 & 18.5 & 0 & 0 & 0 \\
\hline Hyp $20+$ Guo 30 & 10.8 & 7.5 & 11.2 & 8.1 \\
\hline Ino $20+$ Guo 20 & 2.1 & 17.5 & 2.8 & 16.5 \\
\hline Guo 20 & 0 & 0 & 4.1 & 15.0 \\
\hline
\end{tabular}

replaced by a mixture of adenine, $\mathrm{Mn}^{2+}$ or $\mathrm{Fe}^{2+}$ and thiamine in a medium for production of guanine derivatives from hypoxanthine.

b) Concentration of added hypoxanthine and inosine. Production of guanine derivatives at various concentrations of hypoxanthine or inosine was examined. As can be seen in Fig, 5, productivity of guanine derivatives
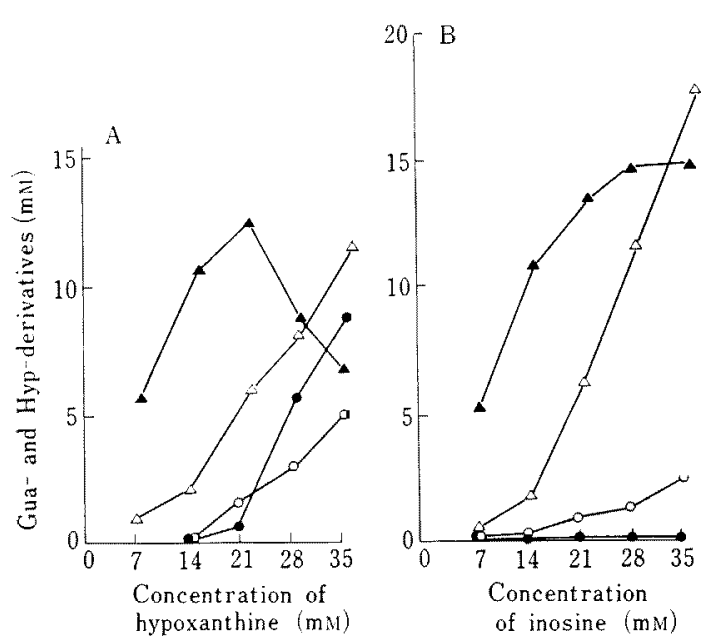

FIG. 5. Effect of Concentration of Hypoxanthine and Inosine.

Cultivation was carried out in a production medium containing $10 \mathrm{~g} /$ liter of yeast extract and indicated concentration of hypoxanthine or inosine for 6 days at $28^{\circ} \mathrm{C}$. After the cultivation, UVabsorbing compounds were determined.

Ino. increased with increasing concentration of hypoxanthine or inosine added in the medium. It is noteworthy that guanosine was sole product at a low concentration of hypoxanthine, while at a high concentration thereof production of guanine was stimulated and that of guanosine was depressed (Fig. 5-A). On the other hand, in the inosine-supplemented medium, guanosine alone was produced irrespective of the concentration of inosine (Fig. 5-B). As will be shown in the following experiment, these phenomena should be resulted from the transribosidation from guanosine to hypoxanthine.

\section{Transribosidation from guanosine to hypoxan- thine}

Whether the washed cells of strain No. 322 can transfer the ribose moiety of guanosine to hypoxanthine in veronal acetate buffer, $\mathrm{pH} 7.0$, was examined. As shown in Table VII marked degradation of guanosine to guanine was observed in the presence of hypoxanthine, but not in the absence of hypoxanthine. The reaction seemed to be accompanied by formation of inosine from hypoxanthine. These results suggest that strain No. 322 possesses a transribosidase activity which transfers ribose moiety of guanosine to hypoxanthine. The fact that guanine was mainly produced in a production 
medium containing a high concentration of hypoxanthine (Fig. 5-A) is well understood on the basis of the transribosidation.

\section{DISCUSSION}

In the present report, it was shown that adenine-requiring or adenine-leaking mutants lacking GMP-reductase of Bacillus subtilis were able to convert exogenous hypoxanthine to guanine derivatives, but GMP-reductaselacking mutants which do not require adenine had not this ability. This fact seems to be related to de novo synthesis of guanosine in Bacillus observed by Nogami et al. ${ }^{7)}$ According to them, the indispensable genetic characters of mutants concerning with guanosine productivity are both adenine requirement and lack of GMP-reductase. It seems reasonable that lack of GMP-reductase is an important factor for accumulation of guanine derivatives, because the conversion of hypoxanthine or inosine to guanine and/or guanosine may occur at nucleotide level: Inosine $\rightarrow$ hypoxanthine $\rightarrow \mathrm{IMP} \rightarrow \mathrm{XMP} \rightarrow$ $\mathrm{GMP} \rightarrow$ guanosine $\rightarrow$ guanine. However, the reason why the adenine-requiring or adenine- leaky property is necessary for the conversion is still unknown, although it is supposed that intracellular adenine deficency resulted from the adenine-requiring or adenine-leaky character may stimulate uptake of hypoxanthine derivatives followed by incorporation of them into IMP in the cells and/or may keep XMP aminase free from inhibition by adenine or AMP. $^{8)}$

\section{REFERENCES}

1) M. Fujimoto and K. Uchida, Agr. Biol. Chem., 29, 1150 (1965).

2) Y. Midorikawa, T. Akiya, Y. Kato, T. Kiyanagi, A. Kuninaka and H. Yoshino, ibid., 36, 1523 (1972).

3) Y. Midorikawa, T. Akiya, A. Kuninaka and H. Yoshino, Proc. 18th Sympositum of Association of Amino acid and Nucleic acid, p. 36 (1969).

4) O. Kanamitsu, Agr. Biol. Chem., 34, 1424 (1970).

5) M. Fujimoto, M. Morozumi, Y. Midorikawa, S. Miyakawa and K. Uchida, ibid., 29, 918 (1965).

6) B. Magasanik and D. Karibian, J. Biol. Chem., 235, 2672 (1960).

7) I. Nogami, M. Kida, T. Iijima and M. Yoneda, Agr. Biol. Chem.., 32, 144 (1968).

8) S. Udaka and H. S. Moyed, J. Biol. Chem., 238, 2797 (1963). 